Vol. 1, No. 2, Juli - Desember 2017

\title{
edureligia
}

\section{ZAKAT DI INDONESIA; SEBUAH REFORMULASI PENGELOLAAN}

\section{I d r u s}

Institut Agama Islam Nurul Jadid, Probolinggo

\section{Info Artikel}

Sejarah Artikel:

Diterima April 2017

Disetujui Juni 2017

Dipublikasikan Agustus 2017

Keywords:

Auditory Intellectually

Repetition (AIR);

Comparative Study;

Expository; Problem

Solving.

\section{Abstract}

This text is a conceptual study from the point of view of Islamic education, which tries to provide perspective from different side, this critical study is more to the reformulation of zakat is the effort of ijtihad in the field of zakat to further streamline the implementation of zakat in the context of space and time. The basic assumption of zalcat reformulation is that charity is a social service and its rules are still loaded with ijtihad. this paper will try to propose the reformulation of zakat in three fields. First, reformulate the sources of zakat. Second, the reformulation of zalcat management. Third, reformulate the distribution of zakat.

\footnotetext{
Alamat Korespondensi:

Gedung E Lantai 1 Fakultas Tarbiyah

PO. Box 1 Paiton Probolinggo, 67291

E-mail: idrus0009@gmail.com
}

ISSN 2549-4821

E-ISSN 2579-5694 


\section{PENDAHULUAN}

zakat disamping sebagai ibadah, juga mengandung dimensi sosial. Dalam surat at-taubah: 103, pelaksanaan zakat di tujukan untuk mensucikan harta dan jiwa orang yang memiliki harta. Selain itu, zakat juga dimaksudkan untuk membantu orang-orang yang berada dalam ekonomi lemah, serta mensyukuri nikmat dan anugrah Allah

zakat menjadi pilar penting dalam islam. Ia senantiasa di sebut Al-qur'an beriringan dengan sholat. Perintah zakat diungkapkan secara tegas dan tata aturannya di jelaskan secara terperinci dalam Al-qur'an dan Al- sunnah. Walaupun demikian, tata aturan itu sarat dengan interpretasi, sehingga dapat mengalami perkembangan sesuai dengan konteks masa dan daerah. Untuk itu, terbuka untuk diadakan reformulasi kontekstual dalam bidang zakat.

Reformulasi zakat merupakan upaya ijtihad di bidang zakat untuk lebih mengefektifkan pelaksanaan zakat dalam konteks ruang dan waktu. Asumsi dasar reformulasi zakat itu adalah zakat merupakan ibadah sosial dan tata aturannya masih sarat dengan ijtihad. tulisan ini akan mencoba mengemukakan reformulasi zakat dalam tiga bidang. Pertama, reformulasi sumber-sumber zakat. Kedua, reformulasi pengengolaan zakat. Ketiga,reformulasi distribusi zakat.

\section{REFORMULASI SUMBER-SUMBER PENGGALIAN ZAKAT}

Pada dasarnya al-qur'an tidak menyebut secara tegas dan terperinci mengenai harta yang dikenai zakat. Menurut al-qur'an dan al-sunnah, jenis harta yang di kenakan zakat ada lima macam. Pertama, emas dan perak (al-naqaid). Kedua, harta tambang (al-ma'adin) dan kekayaan terpendam (alrikaz). Ketiga, harta perniagaan ('urut altijarah). Keempat, tanaman dan buahbuahan (al-zuru' wa al-tsimar). Kelima, binatang ternak, yaitu onta, lembu, dan kambing.

Kelima jenis harta itu secara garis besar dapat di kelompokkan menjadi dua, yaitu harta yg tersembunyi (al-batinah) dan harta yang tampak (al-zahirah). Jenis harta yang tersembunyi antara lain: emas, perak, dan harta perniagaan. Sedangkan harta yang tampak antara lain: tanaman, buahbuahan, dan binatang ternak.
Ukuran zakat itu di berlakukan menurut usaha memperolah harta tersebut. Harta yang di peroleh dengan mudah tampa mengekuarkan beaya maka zakatnya lebih besar dari pada harta yang di peroleh dengan susah paya serta mengeluarkan beaya yg relatif besar. Misalnya, harta yg dialiri hujan lebih besar pengeluaran zakatnya (10\%) di banding tanaman yang diairi dengan air yang di usahakan (5\%), kadar zakat harta temuan (20\%) lebih besar dari pada kadar zakat emas dan perak (2,5\%).

Semua harta di atas harus di keluarkan zakatnya apabila mencapai satu nisab dan selama satu tahun (hawl), kecuali tanaman, bauh-buahan, dan harta temuan. Tanaman dan buah-buahan baru dapat di keluarkan zakatnya apabila sudah panen. Demikian juga, harta temuan yang baru digali seketika harus dikenakan zakatnya.

Pada dasarnya kelima harta tersebut dengan persyaratannya akan sulit dijumpai pada masa sekarang, kecuali harta perniagaan dan harta temuan. Sementara perkembangan ekonomi dunia yang pesat mampu menghasilkan kekayaan yang lebih mudah. Upaya memperoleh kekayaan itu juga tidak di sebutkan secara eksplisitdalamnass, sehingga analisa tekstual memungkinkan terhindar dari pembayaran zakat. Untuk itu reformulasi diarahkan pada dua sasaran, yaitu redefinisi harta zakat dan mengedepankan tujuan syariah dalam memberlakukan harta tersebut.

Emas dan perak dapat diartikan sebagai harta yg berharga dan memiliki nilai. Berangkat dari pengertian itu, semua harta yang memiliki nilai yang tinggi dan beharga sekaligus sudah mencapai nisab dan selama setahun dapat dikenakan zakat. Harta yang berharga dan mempunyai nilai itu antara lain: obligasi, saham, uang, deposito, dan sebagainya. Begitu pula intan, permata, dan sejenisnya dapat disamakan dengan emas dan perak.

Harta perniagaan juga dapat diartikan sebagai kekayaan yang dihasilkan dari usaha bisni, baik berupa barang maupun jasa. Pengertian tersebut didasarkan pada surat al-baqarah: 267. Usaha bisnis tersebut dapat berupa perdagangan, persewaan, maupun profesi. Dengan demikian semua harta yang dimaksudkan untuk diperdagangkan, bila sudah mencapai satu nisab dan selama satu tahun, harus dikenakan zakat, misalnya perdagangan kelapa, unggas, sayurmayur, dan sebagainya. Demikian pula dengan persewaan dan profesi, misalnya persewaan rumah, persewaan kendaraan, profesi dokter, dosen, dan sebagainya.

Tanaman, buah-buahan, dan biji-bijian dapat dikenakan zakat. Hal itu didasarkan pada surat al-an'am: 141 dan al-baqarah 267. Kedua ayat itu 
memberi pengertian bahwa segala yang dikeluarkan atau tumbuh dari bumi harus dikeluarkan zakatnya. Adapun hadist nabi SAW. Mengenai zakat tanaman hanya lima macam yaitu gandum, sya'ir (padi belanda), korma, zaib, dan bijian, tida dapat mentakhsis ayat diatas. Dala kaidah usul figh, dalil yang zanni tidak dapat mentakhsis dalil yang qat'i. Begitu pula hadist nabi SAW. Bahwa tida ada zakat dalam sayur-sayuran adalah tidak sahih sebagaimana yang ditegaskan oleh alturmudhi (W.279H/892M.).

Harta hasil tambang dan harta temuan juga memberi pengertian yang lebih luas, yakni sebagai tambang keras, cair maupun cetakan, demikian pendapat al-syafi'iyah. Bagi hanifiah, tambang yang cair, misalnya minyak, tidak dikenakan zakat. Pendapat hanifiyah itu tampak tida relafan dengan pemahaman umum dari surat albaqarah: 267. Oleh karna itu, minya, logam, batubara, nikel, dan sebagainya harus dikeluarkan zakatnya, yakni seperlima.

Binatang ternak menjadi harta zakat hanya ditentukan pada onta, lembu, dan kambing, sesuai keterangan hadist albukhori. Hanya saja perbedaan ulama terletak pada status binatang ternak yang dikenakan zakat, digembala dengan mencari makan sendiri ataukah diberi umpan. Bagi Abu hanifah (W.81$150 \mathrm{H} / 700-767 \mathrm{M}$.), syafi'i (W.150204H./767-819M.), dan ahmad b.hanbal (W.164-241H./780-855M.) binatang ternak yang mencari makan sendiri saja yang wajib dikenakan zakat. Dasarnya adalah hdith"kambing yang dikembala mencari makan sendiri (saimah al-ganam) dikenakan zakat". Sedangkan malik (W.179/795), ulama madinah, dan allayth (W.175/799) berpendapat bahwa binatang yang diberi umpan, ditunggangi, atau digunakan membajak wajib dikenakan zakat. Dalilnya adalah keumuman hdith"pada setiap 40 ekor kambing harus dikeluarkan zakatnya seekor kambing". Malik tida melihat keterkaitan antara pengembala binatang ternak dengan kewajiban zakat. Justru kewajiban zakat itu terletak pada pertumbuhan binatang itu. Demikian juga, apabila pengeluaran ongkos dijadikan alasan untuk meniadakan zakat oleh mayoritas ulama (jumhur al-ulama'), maka alasan itu kurang kuat, karena pada zakat tanaman juga dikenakan zakat sekalipun dengan mengekuarkan beaya.
Selain itu, meniadakan zakat pada kambing yang diberi makan dengan berpegang pada mafhum mukholafahnya juga kurang kuat, karena dalil umum lebih kuat dari dalil kitab. Tentu saja menganalogikan sesuatu yang tidak kuat juga di anggap kurang kuat. Oleh karenah itu, onta, lembu, dan kambing, baik digembalakan maupun diberi makan, tetap dikenakan zakat.

Jadi, pemahaman harta zakat secara kontekstual akan menyentuh pada semua jenis harta. Apabila hal ini menjadi pegangan tentu hampir semua kekayaan yang di miliki umat islam dapat dikenakan zakat.

\section{PENGELOLAAN ZAKAT OLEH PEMERINTAH}

Pengelolaan zakat adalh kegiataan mengefektifkan zakat agar mencapai tujuan yang diharapkan. Pengelolaan itu antara lain: pengumpulan zakat, pencatatan, penjagaan harta zakat, pembagian zakat, sosialisasi hukum zakat, dan penegakan hukum zakat. Banyaknya tugas itu sulit ditangani secara individual, tetapi hanya bisa dilaksanakan oleh sebuah lembaga atau instansi yang melibatkan kekuatan negara.

Penanganan zakat oleh pemerintah telah disepakati oleh ulama. Dalam al-quran surat al tawbah: 103 mengandung perintah untuk memungut zakat. Perintah itu ditujukan kepada pemerintah yang berhak memungut zakat. Sejarah mencatat, bahwa Nabi SAW. Telah mengutus mu'adh bin jabal pergi memungut zakat. Selain mu'adh, petugas pemungut zakat pada masa Nabi SAW. Antara lain: ibn lutayibah, abu mas'ud, abu jahm, 'uqbah bin amir, al-dahhak, ibn al-qayyim, dan 'ubaidillah bin al-samit. Kebijakan Nab tersebut juga di lanjutkan oleh para khalifah pengganti beliau. Abu bakar pernah memerangi orang-orang yang enggan menunaikan sholat dan zakat.

Banyak keuntungan apabila zakat itu dikelola oleh pemerintah. Pertama, pernah mempunyai majelis para ulama yang bertugas memberikan fatwah. Kedua, pemerintah juga mempunya dapartemen yang menangani kesejahteraan sosial, sehingga memungkinkan membuat data mengenai orang-orang berhak menerima zakat. Ketiga, pemerintah memiliki lembaga penegak hukum, sehingga orang yang enggan membayar zakat dapat dituntut dipengadilan. Keempat, pemerintah memiliki lembaga dakwah yang menyeru umat islam untuk membayar zakat. Kelima, pengelolaan zakat oleh pemerintah akan menjaga kehormatan fakir miskin, karena ia akan menerima zakat dari negara, bukan santunan dari orang kaya. Keenam, orang-orang yang sangat mencintai harta dan berat mengeluarkan 
zakatnya dapat di paksa oleh pemerintah. Ketujuh, kezaliman dengan mebagikan zakat kepada orang-orang tertentu menurut keinginan orang kaya dapat dihindari. Kedelapan, pembagian zakat tidak hanya terbatas fakir miskin saja tetapi golongan lain juga menjadi tanggung jawab pemerintah. Kesembilan, kemungkinan disatukan pajak dalam zakat, apabila hal ini telah disepakati.

Pengolaan zakat oleh pemerintah di atas memungkinkan apabila bentuk suatu negara islam, atau paling tidak membuka peluang diterapkannya hukum islam bai umat islam. Menurut konsrp negara islam, indonesia layak disebut negara islam. Disamping secara suridis konstisusi negar indonesia mencerminkan nilai-nilai keislaman, juga secara sosiologis umat islam indonesia adalah mayoritas. Dengan landasan itu pula, majelis permusyawaratan rakyak akhirnya mapu melahiran undang-uandang tentang pengelolaan zakat.

Legalisasi zakat diperlukan untuk mengontrol pengolaan zakat oleh pemerintah serta menegakkan hukum secara ditengah masyarakat. Sangsi hukum diberlakukan tida saja pada amil zakat yang nakal tetapi juga juga orangorang yang enggan membayar zakat. Selain itu, legalisai akan memudahkan pembagian tugas kepada masing-masing daparttemen dala pemerintah. Dapartemen kehakiman dan kepolisan R.i. dapat diberi wewenanma g untuk menegakkan hukum zakat. Dapartemen dalam negeri dan dapartemen sosial diberi wewenang mendata jumlah orang-orang yang wajib membayar zakat dan orangorang behak menerima zakat. Majelis ulama indonesia bersama organisasiorganisasi ke agamaan di indonesia berwenang untuk memberi fatwa sekaligus berdakwah menganjurkan membayar zakat. Departemen keuangan berwenangan mengelolah keuangan zakat dan pajak. Seangkan departemen agama sebagai koordinator pengelolaan zakat.

Selama ini, pengelolaan zakat di indonesia agama berdasarkan Surat Keputusan Bersama (S.K.B) Mentri Agama dan Mentri Dalam Negri Nomor 29 dan 27 tahun 1991 tentang pembinaan amil Zakat,Infak, dan Sedekah (BAZIS). SKB tersebut kemudian di tindak lanjuti dengan instruksi Mentri Agama Nomor 5 Tahun 1991 tentang pembinaan teknis BAZIS. Lembaga BAZIS tersebut mengelolah zakat dengan pendekatan iman dan takwah. Alhirnya pelaksaan BAZIS tersebut masih dirasa kurang efektif, karna masih banyak umat islam yang enggan membayar zakat. Di samping itu, Departemen Agama, sebagai pengelolah zakat secara resmi kurang mendapat kepercayaan dari masyarakat.

Penting dicatat di sini bahwa legalisasih zakat juga dapat di harapkan untuk dapat menjadi sarana mengentaskan kemiskinan indonesia. Oleh karena itu, upaya penting yang tidak boleh di abaikan adalah mendayagunakan harta zakat secara produktif untuk fakir miskin hal itu dapat di perbolehkan selama ada persetujuan dari pihak dari orang-orang yang berhak menerima zakat. Adapun bentuk produktifitas tersebut tergantung dari kemampuan pihak penerima zakat dalam mengelolah harta. Sebagai contoh,jika penerima zakat dapat mengayuh becak,maka harta zakat itu dpat dibelikan becak yang pada gilirannya di gunakan untuk mencari nafkah demikan pula, upaya menjadikan harta zakat sebagai beasiswa bagi anak-anak bagi keluarga yang kurang mampu juga termasuk pendaya gunaan harta zakat secara produktif.

\section{REFORMASI DISTRIBUSI ZAKAT}

Maksud distribusi zakat disini adlah upaya membagi zakat kepda delapan golongan yang telah disebutkan dalam surat al-tawbah: 60 . Ayat tersebut memberi petunjuk secara pasti bahwa golongan yang berhak menerima zakat adalah: (1) kaum fakir, (2) kaum miskin, (3) para amil zakat, (4)kaum muallaf, (5) para budak, (6) orang-orang yang terlilit hutang, (7) para pejuang di jalan allah, (8) kaum musyafir. Masing-masing golongan tersebut sarat interpretasi dari para ulama

Pengertian fakir dan miskin dapat diklasifikasikan dalam enam pendapat pertama, fair adalah orang yang kekurangan secara ekonomis dan dapat menahan diri dari mintaminta, dan miskin adalah orang yang kekurangan tapi masih meminta-minta. Pendapat ini dikemukakan oleh ibn'abbas (W.68H./687M.), al-hasan, jabir bin abd allah (W.78H./661M.), ibn zayd, al-juhri (W.124H./741M.), mujahhid (W104H.), dan zayd. Kedua, pendapat katadah (W.118H.) bahwa orang fakir adalah orang yang kekurangan dan terkena musibah, sedangkan miskin adalah orang yang kekurangan saja. Ketiga, pendapat al-dahhak bin muzahim dan ibrahim al-naka'i (W.177H.), bahwa orang fair adalah orang yang melakukan hijarah, dan orang miskin adalah orang yang tida melakukan hijrah. Keempat, pendapat ikrima, bahwa fakir adalah orang muslim yang kekurangan, sedangkan miskin adalah dari nonmuslim. Kelima, 
pendapat al-syafi'i (150-204H/757819M.), bahwa fakir adalah orang yang tidak memiliki apapun dan serba kekurangan, sementara miskin adalah orang yang masih memiliki harta tetapi tidak dapat mencukupinya, juga ia punya tempat tinggal tetap. Keenam, pendapat abu-hanifah

(81-150H./700-767M.), bahwa fakir adalah orang yang masih memiliki tempat tinggal dan memiliki harta tetapi tidak dapat mencukupi kebutuhannya sehari-hari, sedangkan miskin adalah orang yang tidak memiliki apapun dan serba kekurangan

Keenam pendapat di atas akan lebih jelas jika dikemukakan pula batasan orang di anggap kaya. Al-jassas (W.370H.) mencatat empat pendapat. Pertama, orang disebut kaya apabila mampu mencukupi kebutuhan keluarganya secara normal. Kedua, orang yang memiliki 40 dirham baru dianggap kaya. Ketiga, orang yang memiliki kekayaan 50 dirham. Keempat, orang yang memiliki kekayaan 200 dirham. Dari pendapat diatas, penulis menganggap orang fakir lebih membutuhkan dibanding orang miskin, karena kata fakir didahulukan atas miskin. Jadi, fair adalah orang yang tidak dapat mencukupi kebutuhannya serta keluarganya dan iapun tidak memiliki apapun kecuali sedikit harta, seperti orangorang mengungsi karena terkena musibah atau orang-orang tunawisma, semetara miskin adalah orang yang masih memiliki harta, tetapi tidak mecukupi. Ukuran kecukupan itu ditukar menurut kondisi dimana ia berada.

Amil zakat adalah orang-orang yang bertugas mengelolah zakat. Menurut ahmad mustafa al-maragih, mereka di angkat dan diberhentikan oleh pemerintah bahkan al-jassas mewajibkan menganan zakat oleh pemerintah lebih lanjut ia mengatakan bahwa pemerintah berhak mengambil zakat kedua kali, walaupun orang yang wajib zakat mengakui telah mengeluarkan zakat. Pegawai amil zakat juga berhak mendapat gaji dari pemerintah. Gaji itu diambil dari kas negara, sedangkan bagian zakat amil di masukkan dalam kas negara. Dengan demikian bagian amil harus disesuaikan menurut bagian harta zakat tersebut.

Pengertian muallaf juga luas. Menurut alalusi (W.1251H./1835M.) yang dikutip said hawwi ada 3 kelompok yang disebut muallaf. Pertama, orang nonmuslim yang lemah imannya. Pemberian zakat kepadanya dimaksudkan agar ia simpati dan mau masuk islam. Kedua, orang islam yang lemah imannya dan diharapkan imannya menjadi kuat dengan diberikan zakat kepadanya. Ketiga, orang yang hendak mencelakakan umat islam. Karenanya, pemberian zakat kepadanya ditunjukkan menarik simpati dan segera menghentikan kekerasannya.

Berangkat dari pengertian muallaf, tidak lah salah apabila harta zakat digunakan untuk misi islam. Sasarannya adalah umat islam yang lemah imannya, serta orang-orang nonmuslim yang diharapkan masuk islam, atau paling tida bersimpati kepada islma. Dewasa ini islam dihadapkan pada tantangan dari pihak nonmuslim secara gencar. Bahkan umat islam dala kondisi lemah dibanding umat lain. Untuk itu, pemberian zakat kepada para muallaf perlu diaktifkan kembali.

Al-riqab (para budak) mengandung dua penafsiran. Pertama, pendapat ali bin abi thalib (19SH-40H./603-1661M.), abu ahnifah, alsyafi'i, dan para ulama yang lan, yaitu budak mukatab. Kedua, penafsiran ibn uma (10SH73H./612-673M.), yaitu pembebasan dari perbudakan. Pendapat yang terahir itulah agaknya yang relafan dengan tujuan zakat, yaitu menegakkan keadilan. Budak muakatab adalah budak yang masih hutang kepada tuannya aas kebebasannya. Agaknya buda mukatab dapat dikategorikan sebagai orang-orang yang di lilit hutang (al-gariming). Termasuk dala pengertian pembebasan dari buda adalah pembebasan tawanan perang atau sandera, karena pembudakan adalah berasal dari pihak yang kalah perang.

Al-garimun diartikan sebagai orang-orang yang dililit hutang yang sulit membayarnya. Mereka melakukan hutang tersebut bukan untuk maksiat kepada allah atau digunakan untuk berfoya-foya, tetapi hutang tersebut digunakan untuk hal-hal yang berguna bagi dirinya atau orang lan. Almawardi (364-450H.) menambah, untuk kepentingan pribadi harus dari orang fakir, semetara untuk kepentingan umum haru dari orang fakir atau orang kaya. Dengan demikian seseorang atau kelompok yang melakukan kegiatan sosial tetapi dana yang dihimpun tidak mencukupi, maka penyelenggaraan dapat meminta zakat atas kelompok ini.

Orang-orang yang berjuang dijalan allah yang diartikan oleh al-maraghi sebagai jalan yang menyampaikan keridlaan dan pahala allah. Termasuk dala definisi ini adalah segala kegiatan yang ditunjukkan untuk kebaikan umat islam, misalnya meramaikan masjid, memberi gaji kepada para ustad, bahkan beasiswa bai umat isla yang menuntut ilmu. Jadi, pengertian jihad allah 
tidak hanya menunjukkan kepada orangorang yang berperang diagam islam, tetapi juga orang-orang menegakkan kepentingan umum umat islam.

Ibn al-sabil adalah orang yang berpergian bukan untuk masiat kepada allah dan ditengah jalan ia kebahabisan atau kehilangan bekal, sekalipun didaerahnyaia adalah orang yang kaya. Pengertian ini dapat diperluas kepada anak jalanan, kaum tunawisma.

Reformulasi ditribusi zakat secara produktif dapat dikemukakan disini. Pertama, bagi fakir miskin yang memiliki potensi untuk berusaha yaitu dengan jalan: 1 memberikan pinjaman modal usaha dalam bentuk pinjaman kebijakan (qard alhasan); 2 membangun sarana-prasarana pertanian dan perindustrian untuk menampung orang-orang miskin yang menganggur; 3 menyelenggarakan sentrasentra pendidikan keterampilan dan kejuruan untuk mendidik para penganggur agar mereka memiliki keterampilan tertentu. Sedangkan bagi fakir miskin yang tidak potensial dan tida prosuktif, dibangun suatu menampungan semacam panti werda untuk menampung meraka secara konsumtif dan manyediakan hidup bagi manula yatim piatu, serta mengadakan sarana dan prasarana rehabilitasi bagi mereka yang cacat

Kedua, bagi muallaf, diupayakan: 1 membantu kehidupan ekonomi para muallaf yang umunnya mereka mengalami kesulian ekonomi akibat berpindah agama; 2 menyediakan dana dan sarana untuk menyadarkan kembali orang-orang terperosok kedalam tindakan kejahatan kriminal dan asosila; 3 membiayai rehabilitasi orang-orang yang terjerumus dalam penyalahgunaan narkotika, penjuadian, dan sejenisnya; 4 membiayai pengembangan kehidupan sosial ekonomi masyarakat tertinggal dan suku terasing; 5 membiayai usaha-usah rehabilitasi kemanusiaan pada umunnya.

Ketiga, bagi golongan riqab diupayakan: 1 membangun pembebasan buruh-buruh rendah dan kasar dari belagu majikannya yang mengeksploitir tenaga buruh atau yang dapat memurtadkan mereka; 2 membantu pembebasan orang-orang tertentu yang dipenjara karena menggunakan hak asasinya dala mebela agama dan kebenaran; 3 membantu kebebasan masyarakat muslim yang tertindas baik sebagai manusia individu maupun sosial; 4 membantu yang terperosok kedalam kemaksiatan karena sudah terlilit hutang untuk dapat bebas dan kembali kepada jalan yang benar.

Keempat, untuk kaum gharimin dapat diuapayakan: 1 membantu atau meminjamkan pembayaran hutang-hutang orang yang jatuh pailit dalam menjalankan kewajibannya; 2 membantu meningkatkan kempuan manajemen bagi orang-orang yang melakukan udaha dengan modal pinjaman berbunga atau memberikan modal usaha tanpa bunga.

Kelima, bai kaum peuang dijalan allah diupayakan: 1 membantu membiayaan tugas negara dala mewujudkan kemaslahatan masyarakat dan meninggikan agama; 2 membantu biaya keamanan masyarakat bai berbagai gangguan dan tindakan destruktif; 3 membantu biaya dalam keadilan hukum bagi warga negara yang tidak mampu; 4 membantu pembangunan dan pemeliharaan sarana dan prasarana umum; 5 membantu pembiayaan usaha meningkatkan sumber daya manusi dala rangka penunaian tugas sosialnya; 6 membantu guru agama diperguruan swasta yang minus penghasilanya.rusakan mendahulu

Keenam, bagi kaun ibn sabil diupayakan: 1 menyediakaan dana taktis bagi musyafir yang kehabisan baiaya dalam perjalanan; 2 membantu para pengungsi baik karena alasan politik, peperangan, maupun bencana alam; 3 membantu para pelajar yang kekyurangan bekal atau biaya.

Untuk mengantisipasi pengakuan palsu sebagi orang yang behak menerima zakat, maka pemerintah perlu meminta bukti atau saksi untuk memperkuat pengakuan itu. Apabila bukti atau saksi tida didapatkan, pemerintah dapat melihat tanda-tanda lahirnya. Kiranya kaidah" mencegah kerusakan didahulukan atas menarik kemaslahatan" dapat diterapkan dalam masalah ini. Oleh karena itu, pemberian zakat kepada orang yang slah masih lebih baik dari pada menahan zakat dari yang mestinya behak menerimanya, demi menghindari kezaliman

\section{PENUTUP}

Peraturan zakat yang diberlakukan pada masa Nabi SAW. Adalah sesuai kondisi ekonomi pada saat itu. Apabila peraturan itu diterapkan pada masa sekarang, niscaya hukum zakat menjadi stagnasi. Oleh karen itu, reformulasi hukum zakat adalah suatu keharusan, agar perekonomian umat islam dapat dibangun dan bangkit sebagai mana dpa masa awal islam.

Reormulasi hukum zakat menyangkut redefinisi sumber-sumber penggalian zakat, reorientasi 
pengelolaan zakat, dan reinterpretasi distribusi zakat. Apabila dilakukan, maka hampir tidak ada harta yang dikenakan zakat. Pelaksaan zakat tidak hanya mensyukuri nikmat allah, tetapi juga untuk mengentaskan kemiskinan dan pemerataan kekayaan dikalangan umat islam. Begitu pula, kegiatan-kegiatan dakwah islam akan berjalan lancar dan ekfektif apabila ditunjang dengan zakat sebagai logistik dakwah. Akhirnya, reformulasi zakat mengupayakan untuk menjungjung tinggi agama dan umat islam. Semoga.

\section{DAFTAR PUSTAKA}

Ali ahmad al-Jurjawi, Hikmat al-Tasyri' Wa Falsafatuh (Beirut: Dar al-Fikr,tt)

Wahbah al-Zuhayli, al-Fiqh al-Islami wa Adillatuh (Beirut: Dar al-Fikr, tt)

Abu Ya,la al-Farra', al-Ahkam alSulthaniyah (Beirut: Dar al-Fikr, tt)

Yusuf al-Qardlawi, al-Ibadah fi al-Islam (Kairo: Maktabah Wahbah, 1995)

Ibnu Majah, Sunan (Beirut: Dar al-Kutub al-Ilmiyah, tt)

Al-Khudari Bik, Ushul al-Figh (Beirut: Dar al-Fikr, 1988)

Al-Turmudhi, Sunan al-Turmudhi (Beirut: Dar al-Kutub al-Ilmiyah, tt)

Badrun Abu al-Aynayn Badran, al-Ibadat al-Islamiyah (Iskandariyah: Muassasah Shabbah al-Jamiah, tt)

T.M Hasby Ash-Shiddiqy, Pedoman Zakat (Semarang: Pustaka Rizki Putra, 1997)

Yusuf Kamal Muhammad, Fiqh Iqtishad wa al-'Am (tt. Sitabars, 1990)

Ibrahim Hosen, "Fiqh Siyasah Dalam Pemikiran Islam Klasik", Ulumul alQur'an (No. 2 tahun 1993)

Abu Bakar Ahmad al-Rassi, ahkam alQur'an (Beirut: Dar al-Fikr, 1993)

Sa'id Hawwa, al-Asas fi al-Tafsir (Kairo: Dar al-Salam, 1989)

Ibnu al-Arabi, Ahkam al-Qur'an (Beirut: Dar al-Fikr, tt) 